\title{
BTESL Students' Perception Towards Literature Subjects
}

\author{
Mohammad A. Al-Saggaf ${ }^{1}$, , \\ Mohammed H. Al-Aqad1
}

Siti Nur Fahihah Ainina Binti Mohd Rafiee1,

${ }^{1}$ School of Education and Social Sciences, Management and Science University, Shah Alam 40100, Malaysia

\begin{tabular}{llllll}
\hline Received: 07.08.2021 & $\bullet$ & Accepted: 28.08.2021 & • & Published: 30.08.2021 & • Final Version: 30.08.2021 \\
\hline
\end{tabular}

\begin{abstract}
This study investigates the students' perception of literature subjects in the Bachelor of Teaching English as Second Language (BTESL) program in a higher education institution in Malaysia and identifies the perception, attitude, and challenges faced by BTESL second third-year students in learning literature subjects. The study involves 188 participants from a Malaysian higher education institute BTESL, second and third-year students. The sample is being chosen based on the literature subjects that have been taken by the sample. A structured questionnaire has been prepared as the instrument of the study. A total of 45 items is designing in 4 different sections, including the demographic section; it applies the 5-point Likert-scales to collect the data from the respondents. The findings show the students have positive perceptions and attitudes in learning literature subjects. There are challenges faced by the student in learning literature subjects that need to be overcome by the educators. Consequently, in ensuring an effective teaching and learning process on literature subject, there must have considered in selecting text to be included in the classroom. The educators play an important role in identifying the student needs in ensuring the success of the teaching and learning process.
\end{abstract}

Keywords: TESL, Perception, Attitude, Challenges, Literature subject, Tertiary education

\section{Introduction}

In the context of education, to improve the student's English proficiency level, Malaysia Blueprint 2025 has encountered the incorporation of literature towards the teaching and learning process. It is where the incorporation appears to be included among primary and secondary education. By that, it does not consider that the incorporation of literature is stopping towards the end of the secondary level of education; the incorporation of literature in English language learning is continuing up to the tertiary level of education. Sivapalan and Subramaniam (2008) explains that that the incorporation of literature is not only being incorporate towards the English mainly courses but as well as engineering courses. It is the incorporation of literature subject is applying to enhance the proficiency level of the students. It is seen that better language proficiency level is not only for educational purposes (Sivapalan \& Subramaniam 2008; Hazhar et al., 2021).

However, there are issues in incorporating the literature components in English language learning in helping the student to improve the proficiency level. Hence, the study of "BTESL second and thirdyear Students Perceptions towards the Literature Subject" is conducted to identify the student's perceptions, attitudes and chaltenges faced in learning literature subject. Especially among the TESL *Corresponding Author:mohammad_ali@msu.edu.my 
students as TESL students are the future teacher who is being prepared by the industry to continue the next educational system. It is because the incorporation of literature does not only help the students to improve the students' proficiency level. It also gives the students exposure to other culture where the students will be able to learn about the culture of the other country in the world.

\subsection{Background of Study}

English language and literature component seem to be correlated. It is because since the year 1970 which is being started by English-medium school. The inclusion of the literature component in English language learning is to enhance the proficiency level of the students. The inclusion of the literature component is not only enhancing the proficiency level of the students but, it also benefits the students by "Valuable Authentic Material, Cultural Enrichment, Language Enrichment and Personal Involvement" in the incorporating of literature component which is being stated by (Collie and Slatter, 1987). Even though there are benefits and advantages of the incorporation of literature component in English language learning, the previous study by Sivapalan and Subramaniam (2008), Habeeb and Firwana (2015), Karakaya, and Kahraman (2013), Dwaik, et al., (2015), Rahim, AlSaggaf (2021) and others, find out the negative attitude, perceptions and challenges faced by the students in learning literature.

This issue is including the selection of the text in the teaching and learning processes which affect the students' perception and attitude in the incorporation of literature component in the English language learning. Besides, according to Naser and Aziz (2017); the students are pursuing the study of literature only occurs for the examination purposes. It will lead to the negative attitudes and perception of the student to participate in the teaching and learning process.

\section{The Role of Literature in Education}

Sivapalan and Subramaniam (2008) did mention the problems encountered by engineering students in the incorporation of the literature subject during the teaching and learning process. The study mentioned that the incorporation of literature component enhances the English language proficiency. The participants are aware of the needed of the English language and its benefit. It is not only used during the education period. However, the incorporation of literature in education did encounter issues among the students. Sulaiman (2015) comes out with the study on evaluating the suitability of Literature in English subject among the IPG TESL students. The difficulties faced by the students are due to lack of exposure to literature which is related to the previous level of education during the primary and secondary level of education by the teachers.

One of the important reasons mentioned by Ghazali, et al. (2009) behind the issues is due to the methods used by the teacher in the ESL classroom in incorporating literature subject which affect the students' performance in the classroom. Based on the issues, the author suggested conducting the study among the students to identify other issues among the students which can be applied to identify MSU SESS BTESL final year students towards the perception in incorporating Literature in English subject. It is because literature is one of the major subjects that need to be taken by the students to complete the study. The previous researchers suggest future research to keep on identifying the perceptions of the students towards the literature. By conducting the study, the new outcome can be achieved; especially in terms of the awareness of the TESL students towards the literature subject. It is because; the future education relies on the current students. The literature 
might be disposed of due to unable of the teachers to apply the literature component during teaching and learning process effectively.

\subsection{The Problem Statement}

Literature is the component that is being incorporated by the education system. It acts as the role of enhancing the proficiency level of the students. According to Naser and Aziz (2017), some students pursue literature learning for examination purposes which the teaching and learning process only occurs until the examination sessions. It leads to the negative attitude and perception of the students towards literature subject. There is a study by Dwaik, et al., (2015) which explores the students' attitudes towards literature subject. According to the study, it is important to identify the attitude of the students to ensure the effectiveness of the teaching and learning process. Therefore, detail study of the Malaysian higher education institute BTESL second and third-year students' perceptions towards literature subject is carried out to identify the issues among Malaysian higher education institute BTESL second and third-year students.

The previous study on the challenges and perception towards the incorporation of literature in the classrooms shows the low performance towards the literature subject. Suarna (2008) come out with the results of the engineering students who feel unnecessary of the incorporation of the literature subject as they are engineering students due to the text selection which is not comprehension able for the students to understand and lose the focus as cited in Gazali et al., (2009). The same issues probably being face by the Malaysian higher education institute BTESL students in learning literature subjects.

\subsection{Research Questions}

1) What are the MSU BTESL second and third-year students' perceptions towards literature subject?

2) What are the MSU BTESL second and third-year students' attitudes towards Literature subject?

3) What are the MSU BTESL second and third-year students' challenges in learning Literature subject?

\subsection{Conceptual Framework}

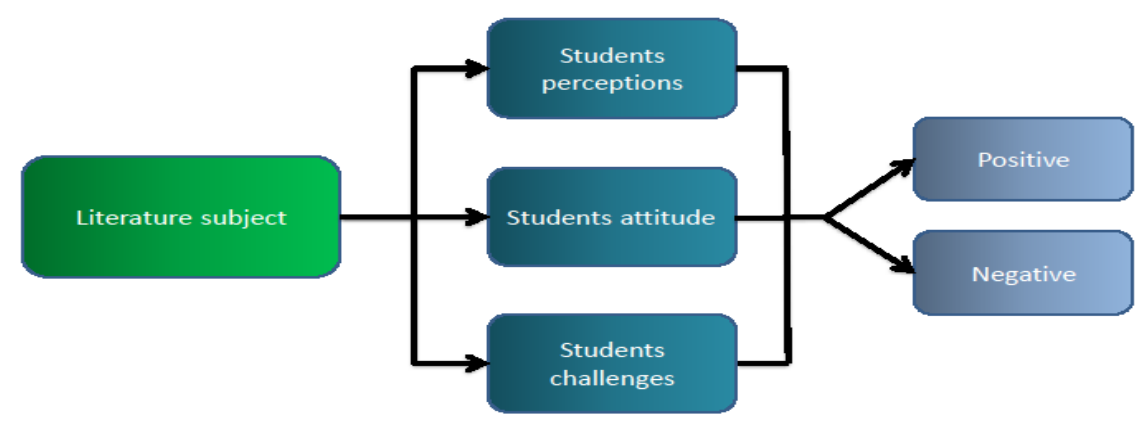

Figure 1.6 Conceptual Framework 
Literature in education acts as the role of enhancing students' proficiency level in English language learning. The inclusion of the literature component is mentioned in the Malaysia Blueprint. It helps in improving the proficiency level of the students in English language learning. The conceptual framework explains the movement involves in conducting the study. Literature subjects are the course outline of TESL courses that need to be taken before the practicum session. The identifying of the students' perception, attitude, and the challenges faced will encourage the students to be aware of the role of literature in education. The results of the positivity and negativity can figure out. The results of the findings will help educators in identifying the challenges faced by the students. It can also help the students themselves in ensuring the effectiveness of the teaching and learning process. It will also help the TESL students explore the issues they might face during the practicum session during the teaching and learning process.

\section{Literature Review}

Literature is an art of the language which is exposing the culture of the language in creative expressions. It is one of the ways to explain the culture of a language that can be considered an authentic material where the real situation of the culture is being explained according to the era. This is how the culture is being passed down to the new generations by the elders. It also acts as guidance and reference. Through literature, the next generations can learn the life of the past generations, and it will not be forgotten as it is being written even though the last person of the previous era had deceased. Literature is also being used to explain the history of the culture and the situations that had occurred in the past. Each language has its Literature explaining the culture. English literature is one of the important kinds of literature that is being incorporated into English language learning. English language learning is not specifically about the language itself but includes understanding the culture. Literature is also one of the written media for people to express their feelings or share their own experiences. This is how the explanation of the culture is being applied. Other than having creatively written text, literature also widens the information on the culture of the language.

\subsection{Literature in Education}

The inclusion of Literature in education had been applied since 1970 by the English-medium school. Lim (2015) cited by Taharuddin (2018), explains that the first program implemented by the Ministry of Education (MOE) was the incorporation of literary materials into English Language Program (ELRP). Many programs are being implemented in education. One of them is the incorporation of literary text into the education system, but the literary text had been slowly being overlooked due to the 'Dasar Pandang Ke Timur' slogan promoted by our fourth Prime Minister. This slogan left quite an impact on the Malaysian education system. Hence, the Ministry of Education had come out with a requirement for every student to learn English as their second language which is also aligned with the need for proficient English speakers in the working world. Based on the results, the importance of the English language can be seen clearly, and it should not be abundant as the language itself is used for educational purposes to promote globalization and boost the world economy.

Literature incorporation is being implemented to improve the student's English language proficiency. According to Taharuddin (2018), learning English is not focusing solely on the examination purposes; it is also to ensure the globalization of the literature components as well as increasing the numbers of proficient English speakers. Like the findings of Sivapalan and Subramaniam (2008), literature did help the students in improving their English proficiency level. 
Therefore, Taharuddin (2018) also agrees that literature is the best material in teaching English subject. This is to ensure the sufficiency of language learning being applied by other courses (Sivapalan \& Subramaniam, 2008). Also, in the findings of his previous research, his respondents, the engineering students agreed that the inclusion of literary text in the learning process helped to enhance their English level of proficiency.

The literature role highlighted in the Malaysian Blueprint and the syllabus of primary to tertiary education is to help improve the students' proficiency level in English language learning, with different levels and sets of materials to be included throughout the teaching and learning process. Literature implementation helps the students improve their English proficiency level; therefore, the texts that are being used need to be authentic. This can be seen through the text, where several famous writers such as Shakespeare, Sherlock, Roal Daph shared the Western cultures through their written texts. Thus, it helps the students to build and develop knowledge and a better understanding of the culture and social life of people in the past.

\subsection{Models Involved}

The inclusion of Literature in education acts as a role to enhance the level of students' proficiency in various ways. Collie and Slatter (1987) explain the benefits of literature included in the learning process which can be seen through the relation of a model developed by Carter and Long (1991) that can be applied in the teaching and learning process.

- Valuable Authentic Material

- Cultural Enrichment

- Language Enrichment

- Personal Involvement

(Collie and Slatter,1987)

- Cultural Model

- Language Model

- Personal Growth Model (Carter and Long, 1991)

To ensure the success of literature incorporation in the teaching and learning process, several researchers had been conducting research to identify the perception, attitudes, and perceived need in the incorporation of the literature into the teaching and learning process. Even though there are various numbers of previous research on explaining the benefits and advantages of having literature as one of the components included in the education syllabus, some issues had occurred in implementing literature in education which includes TESL students who are at the tertiary level. Thus, there is the need to research the students' perceptions of literature in the teaching and learning process, their attitudes towards literary incorporation and the perceived need in incorporating literature in education. According to the result of the previous, many of the students are unaware that literary inclusion in education plays a role in enhancing their English proficiency.

\subsection{Previous Studies}

In the teaching and learning process, it is vital to consider students' perceptions towards it as this is to ensure the effectiveness of the process. Different students have a different set of personality and thinking skills; thus, it leads to the difference in terms of cognitive thinking and perceptions towards the incorporation of literature as one of the main subjects in the English language teaching and learning process. As mentioned by Othman et al., (2015) in their previous study, the students were 
having difficulties with the text selection. Similarly, Sulaiman (2015) examined the suitability of the text used among TESL students in Institut Pendidikan Guru (IPG). The study stated that literary selection plays a significant role in the teaching and learning process to help the students to actively engage in the classroom. The poor consideration of the text selection will affect the students' interest in learning English.

Sivapalan and Subramaniam (2008) conducted a study of the use of literary text in English language learning among engineering students. They found out that the students thought that learning Literature is unnecessary. Based on this result, it clearly illustrated that the students did not grasp the importance and benefits of learning Literature as it is said that the main objective of Literature inclusion into the syllabus is to enhance the proficiency level of the students. Literature acts as a medium to reflect on a certain cultural role and is an important tool used to learn English and make the lesson more enjoyable.

Students' perception is essential when it comes to incorporating literature into the syllabus. Students' attitude will be affected based on their perceptions of the literature. Students required an explanation of the benefits and roles of the Literature incorporation into their syllabus. They need to be clear that by learning Literature, they can improve their English proficiency level. Several researchers like Habebb, et al. (2015), Karakaya, et al. (2013), Al-Saggaf, et.al. (2021) Raghad et al., (2015) also shared the same opinions regarding the benefit of Literature inclusion into English syllabus. However, the effectiveness of the role of literature is not able to be achieved if students have a negative perception towards it.

Kaur, et al. (2010) mention that the students agreed one of the challenges faced by them is that the teacher is not able to deliver the context effectively. Various research had come up with results showing that students have positive attitudes to learn Literature, but they seemed to lose interest because the text is chosen, and the teaching and learning process is not interesting. Teacher's way of delivering the text context also affects students' interest and perception. There are quite a few research being conducted on non-TESL students who are using the literature component in English language learning, where the inclusion is aligned with the Malaysia Blueprint statement, stating the importance of literary text in enhancing the proficiency level of the students who are learning English.

These challenges need to be overcome to ensure that the literature role is effectively being applied towards the students. Based on the study conducted by Othman, et al. (2015), students' achievement is not predictable especially in critical analysis or personal response towards the literary texts. This result explains that the students are having difficulties answering questions that involve critical analysis and personal response, which is closely related to students' understanding of the literary text used. These findings can act as guidance or reference for the teacher to overcome these challenges and help the students to understand the literary text better.

\subsection{The Text Selection}

Text selection is the most common issue that affects students' negative perceptions and attitudes leaning to the difficulties and challenges in implementing literature in the teaching and learning process. The lack of engagement between teachers and students during the teaching and learning process contributes to the build-up of students' negative attitudes and perceptions. Teachers play an 
important role in ensuring the text selection follows the needs of the students as well as the needs of the education systems which is enhancing the proficiency level of the students by incorporating a Literature component into English language learning. Collie and Slatter (1987) mention the benefit of literary texts in providing the students with authentic valuable materials, language enrichment, cultural enrichment and personal enrichment that can only be achieved if the literary texts used are suitable for the students' English proficiency level.

According to Tevdoska (2016), text selection needs to meet the level of the students' proficiency; meaning that it needs to meet the maximum level of proficiency which is one level higher from the students' current proficiency level. This is to ensure that students can follow the lesson and actively participate during the teaching and learning process and respond positively to the learning process. The text selected type must not be culture oriented as the role of Literature is to encourage the students to learn the English language. Literary texts with complex language and culture will lead to negative attitudes among the students. Students' negativity is in arrears to the perceptions of the western culture that involve political issues Alfauzan, et al. (2017).

Since there is a need to consider the level of the text, Bibby (2014) mentions that there are five criteria that need to be investigated by teachers when it comes to choosing the suitable literary text used during the teaching and learning process, involving elements such as lexis, syntax, length, interest, and familiarity. This is to ensure that Literature incorporation into the English language teaching and learning process is successful and can enhance the students' English proficiency level. The chosen texts must meet the students' first and second language levels as it will encourage them to actively participate and produce favorable learning conditions in the classroom. The syntax and lexical criteria must also be aligned with the students' level of proficiency. Thus, it is important not to select any literary texts written with difficult vocabularies and complex sentence structure to cater to a classroom with students of mixed abilities and different English language proficiency, especially for students in tertiary education. Text sentence structures must follow the simple basic clause such as being written in simple sentences, allowing the students to comprehend the texts better. This is in line with the main role of teaching Literature to students which is to enhance their English language proficiency through literary texts that are suitable for them. Complex literary text can later be taught to students who are taking Literature as their major subject.

\section{Methodology}

The existing study occurs among the bachelor students of Teaching English as Second Language (BTESL) between second and third-year students. This study acquires a quantitative method of study, which is the most suitable approach to apply in looking for the answers to the research questions. The study also involves the steps of ensuring the validity and reliability of the study by using the SPSS. Literature is one of the components that need to be enrolled by BTESL students before going for a practicum session. It is because literature is one of the components that are being included in the syllabus, which will help the students in enhancing the proficiency level of the students. The reason for the inclusion of literature subject as the component that needs to be completed by the TESL students before being sent to the school. The incorporation of the literature subject is not only looking forwards to completing the subject before graduation, but it is to ensure that the teachers are well prepared to teach in a real-life situation as literature is the component that is being included in the syllabus on the primary, secondary, and tertiary level in the education system. 
The samplings of the study involved 188 samples from a total of 350 students of the population of MSU SESS BTESL second and third-year students. The sample size involves in this sample of the study is $95 \%$ which is $5 \%$ of the margin error. It is in line with the need of completing or nearly completes the literature subjects to ensure the validity of the reason of the study which consists of the Language Proficiency Literature: Introduction to Literature in Education, Teaching Literature in Education, Theatre in TESL and Critical Appreciation In Education subjects. These are the steps of the subjects that need be complete and followed by the TESL students as each of the subjects carries different outcomes that act as the role of the helper in enhancing the students' proficiency level. TESL students are the students that are being prepared to become a teacher which will be sent to school. It is where the used of literature as one of the media in teaching and learning of English language subject will be applied.

In ensuring the validity of the data collected, the purposive sampling is applied in the study in ensuring the sampling is the population that is familiar with the literature subject. This will bring precise results based on the authentic sampling that is being collected by the accurate population towards the study. Thus, the study is being conducted is to ascertain the perceptions of the TESL students towards the literature subject which involving the perception, attitude, and the challenges face in learning literature subject. It is also to identify the consciousness of the students towards the importance of the literature subject which will be used during the teaching practicum session in the classroom to teach the students. Literature is a component that is being implemented with the conscious of the education system which is enhancing the proficiency level of the students.

Validity and reliability are the criteria that need to look into in conducting research. Thus, in ensuring the validity and reliability of the instruments of the study, a pilot study had been occurred by 43 samples from the same population. The total of the data is being computed and analyzed by using the SPSS to figure out the results of the reliability before being distributed and applied in the real data collection of the study. Based on the pilot study that has been conducted towards 43 samples, 0.856 seems to be the results of the Cronbach's Alpha and 0.830 of the Cronbach's Alpha on Standardized Items with the means 3.259.

\subsection{Instrument}

The questionnaire has been adapted and modified by two previous studies which are from Sivapalan and Subramaniam. (2008) introduced on the study of The Incorporation of Literature in the English Language Program for Engineering Students which is looking at the perception, attitude and the perceived needs of the students; meanwhile, Othman, et al. (2015) conducted a study on Personalizing Learning of English Literature did look at the perceptions and the challenges faced by the students in learning literature subject.

The study used the online survey to collect the data towards 188 samplings of the population of the study and 43 samples of the same population on the pilot study, which is being conducted before the actual data is being collected. Collection of the data used the same platform. The questionnaires were segmented to four sections including a demographic section for the first section. The questionnaires consist of 4 sections including the demographic of the respondents as the records; Section B consist of 12 items of the students' perceptions; Section C consist of 12 items on the students' attitudes and Section D consists of 13 items on the challenges encountered by the students which bring the total number of the items used in the study to 45 items. Each of the sections of the questionnaires is 
answering the research questions and research objectives of the study. The items consist of 5-point of Likert scale that can be chosen by the respondent in answering the survey according to their agreements. The range of the scales is from 1 (strongly disagree), 2 (disagree), 3 (neutral), 4 (agree) and 5 (strongly agree).

\section{Findings \& Discussion}

\subsection{Research Question 1:}

What are the Malaysian higher education institute BTESL second and third-year students' perceptions towards literature subject?

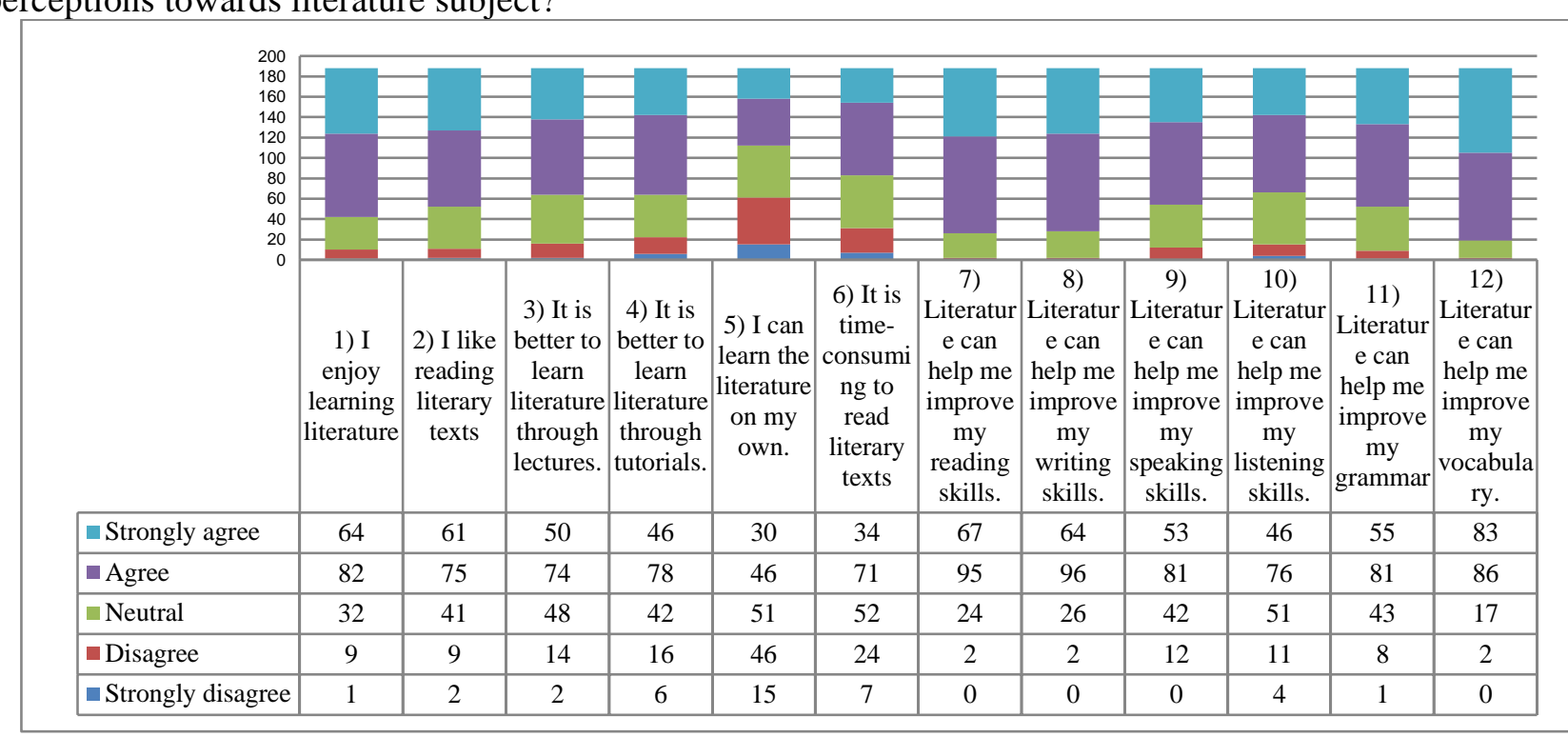

Figure 4.1 Research Question1

Table 4.1 Research Question 1

\begin{tabular}{rccccccc}
\hline & Mean & Minimum & Maximum & Range & $\begin{array}{c}\text { Maximum / } \\
\text { Minimum }\end{array}$ & Variance & N of Items \\
\hline $\begin{array}{r}\text { Item } \\
\text { Means }\end{array}$ & 3.894 & 3.160 & 4.330 & 1.170 & 1.370 & .101 & 12 \\
\hline
\end{tabular}

Based on the results obtained; most of the pupils agreed with the items included. Followed by strongly agree, neutral, disagree and strongly disagree. It represents the total mean score for the items of MSU SESS BTESL second and third-year students' perception towards learning literature subjects to 3.994 .

The findings show that most of the respondents are having positive perceptions of the literature subject. From the responses of the study, most of the respondents are aware of the role of literature in education, especially as TESL students. This is because; TESL students are being prepared to teach the English language in the classroom. The perceptions will affect the outcome of the TESL students as a teacher in teaching the English language. As stated by Sivapalan, Subramaniam (2008) where the role of literature is to help improve the students' proficiency level in the English language. According to Taharuddin (2018), this is because literature is the best material that can be used to apply and improve the English language. 
Literature did help in improving the listening, speaking, reading, writing together with vocabulary and grammar. This is where the selection of the text applied in the classroom which acts as the materials in learning the English language. The inclusion of the variety of the text will expose the students on the different language used in the text. This is where the benefits of inclusion literature component can be seen. Collie and Slatter (1887) stated on the "valuable authentic material, cultural enrichment, language enrichment and personal enrichment" as the benefits of literature in education.

\subsection{Research Question 2:}

What are the Malaysian higher education institute BTESL second and third-year students' attitudes towards Literature subject?

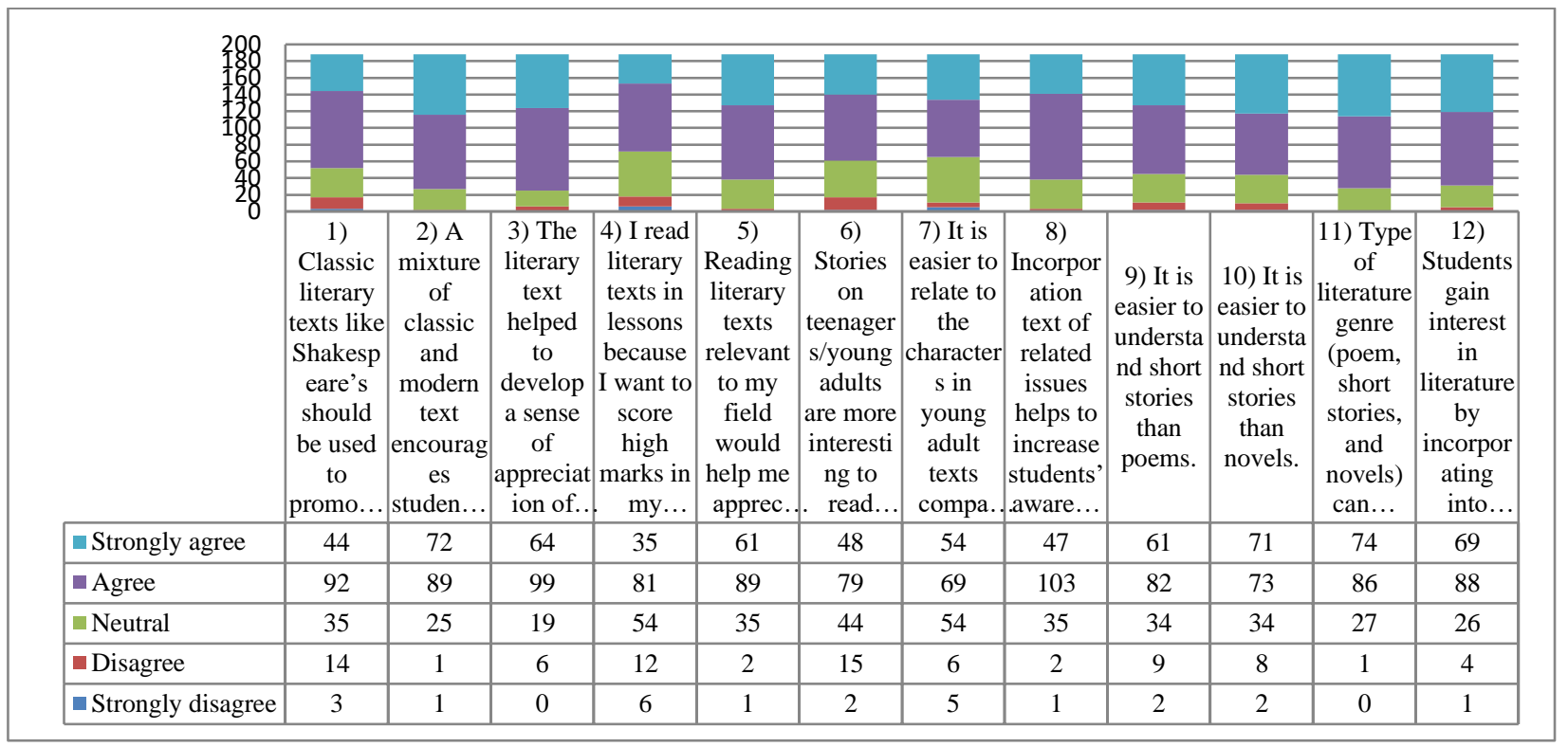

Figure 4.2 Research Question 2

Table 4.2 Research Question 2

\begin{tabular}{cccccccc}
\hline & Mean & Minimum & Maximum & Range & $\begin{array}{c}\text { Maximum / } \\
\text { Minimum }\end{array}$ & Variance & N of Items \\
\hline \multirow{2}{*}{ Item Means } & 4.020 & 3.676 & 4.239 & .564 & 1.153 & .032 & 12 \\
\hline
\end{tabular}

The results show that students agree with most of the items. Followed by strongly agree, neutral, disagree and strongly disagree. It concludes the total of the results obtained for the mean of the items of Malaysian higher education institute BTESL second and third-year students' attitude towards learning literature subject to 4.020 .

Based on the results, most of the responses are having a positive attitude towards the literature subjects. The responses of the respondents agreed on the inclusion of the classic and mix text in the teaching and learning process. Based on the responses, the students can create an appreciation of the literature that is being included in the teaching and learning process. The benefits of the literature component can be seen which is being mentioned by Collie and Slatter (1887). The appreciation is not only for the language itself, but it is also involving the appreciation towards the culture of the origin of the language. The ability to appreciate the text will lead to a better attitude. This is where the students can give full commitment to the study of literature. This will also encourage the students 
to deliver self-expression and opinion by understanding the text which is also being mentioned by Premalatha (2009) cited Naser and Aziz (2017).

The findings show that the students are having a positive attitude towards literature subjects and the inclusion of a mix of modern and classic in the teaching and learning process. There are also responses to the selection of the text. The students prefer having young adult text compare to an adult text which is easy for the students to relate the characters. This brings to the important considerations need to be a focus by the educators especially the length in choosing the text to become as input in the classroom as cited in Dwaik, et al., (2015).

\subsection{Research Question 3:}

What are the Malaysian higher education institute BTESL second and third-year students' challenges in learning Literature subject?

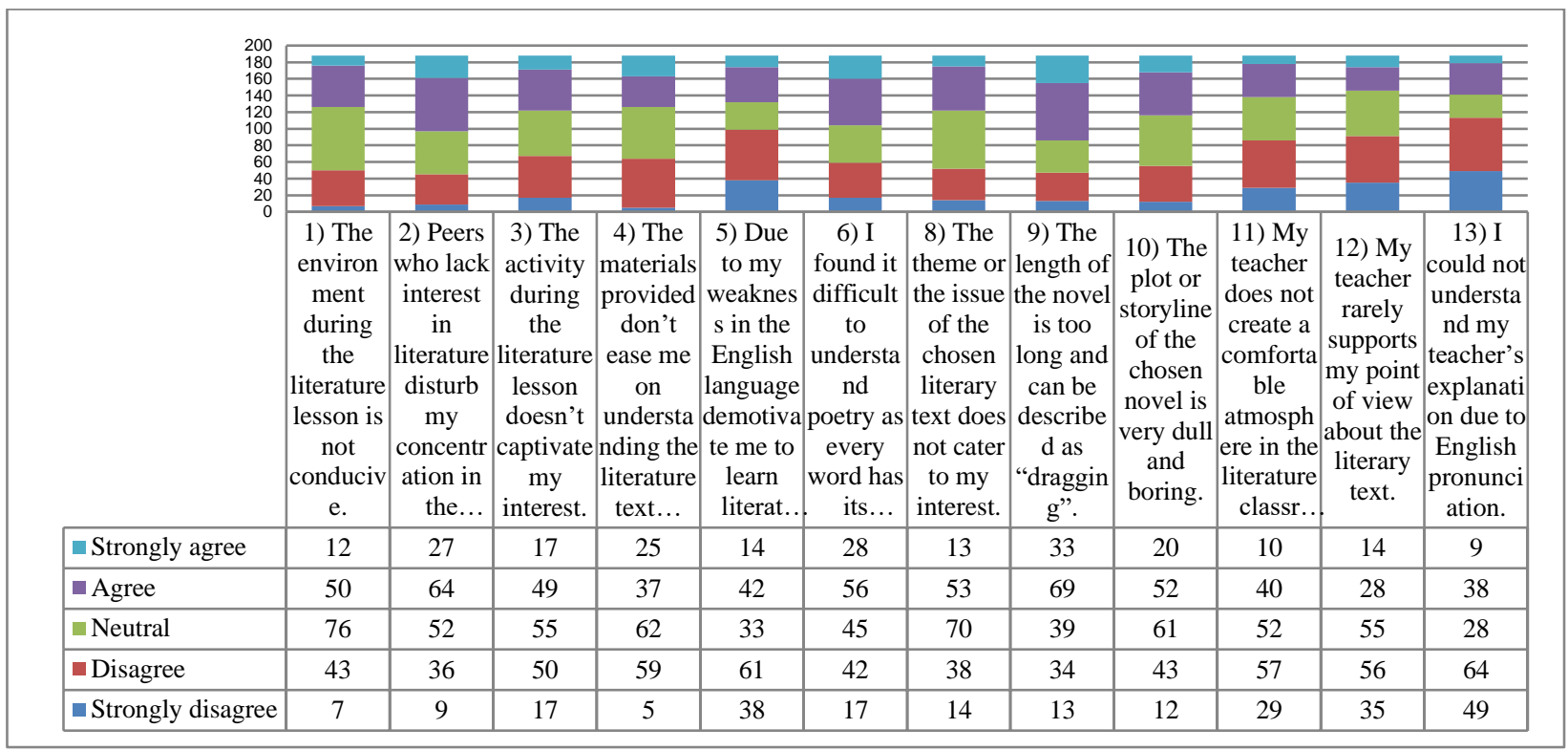

Figure 4.3 Research Question 3

Table 4.3 Research Question 3

\begin{tabular}{rccccccc}
\hline & Mean & Minimum & Maximum & Range & $\begin{array}{c}\text { Maximum / } \\
\text { Minimum }\end{array}$ & Variance & N of Items \\
\hline $\begin{array}{r}\text { Item } \\
\text { Means }\end{array}$ & 2.980 & 2.436 & 3.399 & .963 & 1.395 & .085 & 13 \\
\hline
\end{tabular}

The results shoes that most of the students answered neutrally for the items included. Followed by disagreeing, agree, strongly disagree, and strongly agree. It brings the total mean of the Malaysian higher education institute BTESL second, and third-year challenges faced in learning literature subjects' items to 2.980 .

Based on the items involved in the section of challenges faced by the students in learning literature subject, there few challenges faced by the students need to be overcome and focused on ensuring the effectiveness of the teaching and learning process. Most of the respondents answered neutrally on the items of the environment is not conducive during the teaching and learning session. According 
to Alfauzan and Hussain (2017), in the previous study, the perceptions and the attitude of the students do not only rely on the text but also on the classroom setting during the teaching and learning. This can be considered as the challenges faced in learning literature subject. It may relate to the technical issues and the size of the classroom used. The uncomfortable classroom may lead to the unable to give full attention during the teaching and learning process, including the technical issues related to the projector and sound system involves in the classroom setting.

Based on the responses, the students face challenges that need to be overcome in ensuring the success of the teaching and learning process. The most challenge faced by the students is where the length of the text is too long and dragging. These issues might lead to a negative perception and attitude because the students are not able to pay attention to the inclusion of the long text. Tevdoska (2016) mentioned in the study where the selection of the text needs to meet the level of the students' proficiency which conclude that the maximum level is one level up from the students' proficiency level.

\section{Limitation of Study}

Due to the pandemic issue, the study is having difficulties in collecting the data among the sample of the population. The overall populations of second and third-year students are 350. From the total number of populations, 180 samples are needed in answering the survey with 5\% margin error. Since this study applied purposive sampling, where the data will only count if the respondents have or currently taken at least one literature subject, it is challenging to ensure the data's usage. This is because; the first literature subject that is being taken by second-year students is in the second semester of the second year. It is cause difficulties in reaching the second-year students due to the pandemic issues. This is because the collection of the data needs to be occurred by using $100 \%$ online platform.

This study manages to collect the data towards 196 respondents by sending the link of the survey personally to each of the students through social media. From a total of 196 respondents, eight of the responses are being rejected. This is because the respondents have not taken any of the literature subjects. The data from the students who have not taken the literature subject will not be taken as the findings of the study due to the type of sampling apply in the study.

The limitation of the collection of the data is due to the current issues of Covid-19 which affect the whole world. This is the issues where it cannot be avoided. In the future study, a method of spreading the instruments virtually will be suggested to ensure the better collection of data among the MSU SESS BTESL second and third-year students. This is because; the collection of the data can be done by joining the literature classes with the permission of the lecturer.

\section{Recommendation}

Further study is being suggested in identifying the challenges faced by Malaysian higher education institute BTESL second and third-year students towards the literature subjects. A qualitative method of study will help the educators to identify the issues and challenges faced by the students in details. Interview and observation need to be done in figure out the suggestion of the methods, materials and the text used during the teaching and learning process. Other than conducting a survey, detail explanations towards the preferred learning style need to be identified. By conducting the qualitative 
study, educators can get to know the proficiency level and students' preferences in learning literature subject better.

This is because, as being mentioned by McRae (1991), there are considerations of the students need to look into in selecting the text. This is because; by knowing the students will only lead to a better text selection. This will lead to a better performance of the students with an effective teaching and learning process. Al Aqad, M. H. (2018) did also mention the needs of identifying the students' attitude in the classroom is very significant to ensure the effective teaching and learning process. This will also lead to the actual role of literature in education which is to enhance the proficiency level of the students.

\section{Implication of the Study}

The previous study shows numerous results of the students' positive and negative perceptions and attitude towards the literature subject. Intentionally, most of the challenges and difficulties are based on the selection of text include in the teaching and learning process. There are also results where the students are not able to relate the literature subject to English language learning. The classroom setting is also being considered as one of the challenges faced in ensuring the effectiveness of the teaching and learning process.

The issues encountered in the previous study have brought to the current study, identifying the students' perception, attitudes, and challenges faced in learning literature subject. The findings are showing the positive perceptions and attitude towards the literature subjects. This shows that the Malaysian higher education institute BTESL second and third-year students are aware of the role of literature in Malaysia education. Furthermore, the TESL students will be sent to the school for completing the practicum session. This is where the teaching and learning process will apply the literature component in English language learning.

Thus, the issues encountered in the study will not only give educators the ability to know the solution to conduct a better teaching and learning process. The issues will also give and exposure to the TESL students who will be going to the practicum session. This is because; the TESL students might be facing the same issues during the teaching and learning process. It can help to prepare the students before being sent to school.

\section{Conclusion}

Identifying the students' perception, attitude and challenges face in learning literature subject is very important in ensuring the effectiveness of the teaching and learning process. By conducting the study, the issues occur in the teaching and learning process will be able to identify. Referring to the study, the results reveal positive perceptions and attitudes of the TESL students towards the incorporation of the Literature component in learning the English language. It includes listening, speaking, reading and writing skills. It validates the role of the Literature component as an efficient tool in learning the English language. Sivapalan, Subramaniam (2008) have proved it, the role of Literature is to help in improving the proficiency level of the students in the English language. According to Taharuddin (2018) Literature component is the best material that can be used to apply and improve the English language. Therefore, as an educator, TESL students need to understand the role of Literature in learning the English language. This will help the educators create a better teaching and learning process, especially involving selecting the text to be included in the classroom. Besides the physical setting of a classroom, the study shows the text selection is one of the challenges 
faced in incorporating Literature in learning the English language. Most of the students faced challenges in understanding the poem as each word contain its meaning. Therefore, considerations need to be the focus in choosing the suitable text. It ensures a better understanding and successful teaching and learning process. The negativity of the students' perception and attitude will lead to unsuccessful teaching and learning process. These will also affect the performance of the students in the classroom. By conducting this study, the TESL students will be able to identify the issues and give exposure to the issues that might be facing during the practicum session. This is because the literature component is an important component that is being incorporated in the syllabus to help in improving the proficiency level of the students in learning the English language.

\section{REFRENCES}

[1] Abrahamjan, A. (2020). The Civil Service Procedures and Purpose for Public Sector Employees (Doctoral dissertation, California State University, Northridge).

[2] Al Aqad, M. H. (2018). Fever of Code-switching and Code-mixing between Arabic and English in School's Classrooms. Translation Journal, 4, 1-15.

[3] Alfauzan, A. H., \& Hussain, A. G. (2017). Attitude towards and Perception of Literature in EFL Setting: A Case Study on QU Male Undergraduate Students. English Language Teaching, 10(1), 1-17.

[4] Al-Saggaf, M. A., Al-Aqad, M. H., \& Govindasamy, V. (2020). The Key Factors Affecting English Reading Comprehension Among Malaysian Students. Psychology and Education Journal, 57(9), 2496-2503.

[5] Bibby, S. (2014, November). Criteria and Creation: Literary Texts and a Literature Textbook. The Journal of Literature in Language Teaching, 3(1), 20-31.

[6] Bobkina, J., \& Dominguez, E. (2014). The use of literature and literary texts in the EFL classroom; between consensus and controversy. International Journal of Applied Linguistics and English Literature, 3(2), 248260.

[7] Collie, J., \& Slater, S. (1987). Literature in the language classroom: A resource book of ideas and activities. Ernst Klett Sprachen.

[8] Dwaik, R., Shrouf, S., \& Sahib, B. (2015). An Exploration of Freshman Students' Attitude towards English Literature. Arab World English Journal (AWEJ) Vol, 6.

[9] Elena, S. T. (2016). Literature in ELT setting: Students' attitudes and preferences towards literary texts. In International conference on teaching and learning English as an additional language (Vol. 14, No. 17, pp. 160-169).

[10] Fehaima, A. (2017). EFL Learners 'responses and Attitudes Towards Literary Texts: The Algerian Context. European Journal of Research in Social Sciences Vol, 5(3).

[11] Gubair, D. M., \& Eltahir, S. A. (2019). Challenges to Teaching English Literature in Sudan from a Teacher's Perspective: A Case Study of Khartoum University. International Journal of Science and Research (IJSR), 8(3), 828-835.

[12] Habeeb, A., \& Firwana, S. (2015). IUG English Major Education-Track Students' Attitudes Towards Literature Courses. IUG Journal of Humanities Research, 23 (2), 1-11.

[13] Hazhar, R. A., Shabana . K, \& Mohammed, O. (2021). Literary Parody of Russian Communism Harmonizing to George Orwell's Two Novels "Animal Farm" and "Nineteen Eighty Four". International Journal of Language and Literary Studies, 3(2), 216-228. https://doi.org/10.36892/ijlls.v3i2.554

[14] Hussein, E. T., \& Al-Emami, A. H. (2016). Challenges to teaching English literature at the University of Hail: instructors' perspective. Arab World English Journal (AWEJ), 7(4).

[15] Karakaya, E., \& Kahraman, A. (2013). Students' Attitudes Towards Literature Use. International Journal of Applied Linguistics and English Literature, 2(5), 155-166.

[16] Muthusamy, C., Marimuthu, R., Michael, A. S., Chazali, S., \& Veeravagu, J. (2010). Literature learning in the Malaysian ESL classroom: a Uitm experience. Journal of Language Teaching and Research, 1(1), 6976.

[17] Muthusamy, C., Salleh, S. M., Michael, A. S., Arumugam, A. S., \& Thayalan, X. (2017). Methods used in teaching and learning of literature in the ESL classroom and adult learners' attitude. Journal of Applied Linguistic and Language Research, 4(2), 17-25. 
[18] Naser, S. H. M., \& Aziz, A. A. (2017). Students' Perceptions of the text selection in the Literature Component. In National Pre-University Seminar (pp. 226-236).

[19] Othman, N. I., Shah, P. M., Karim, A. A., Yusof, A., Din, R., Ramli, N. A., \& Salleh, N. S. M. (2015). Personalizing learning of English literature: Perceptions and challenges. Journal of Personalized Learning, 1(1), 104-112.

[20] Rahim, R. N. B. A., \& Al-Saggaf, M. A. (2021). Students' Perception Towards Flipped Classroom Approach in The Islamic and Asian Civilisation Studies (Titas). Journal of Translation and Language Studies, 2(1), 1-18. https://doi.org/10.48185/jtls.v2i1.135

[21] Sidhu, G. K., Fook, C. Y., \& Kaur, S. (2010). Instructional Practices in Teaching Literature: Observations of ESL Classrooms in Malaysia. English Language Teaching, 3(2), 54-63.

[22] Sivapalan, S., \& Subramaniam, G. (2008). The Incorporation of Literature in the English Language Program for Engineering Students: Learner Interest and Perception. 3L: Language, Linguistics, Literature ${ }^{\circledR}, 14$.

[23] Sulaiman, N. (2015). Literature in English: Evaluating its Suitability for Semester 1, PISMP (Bachelor of Education. Jurnal Personalia Pelajar, 18(2), 87-95.

[24] Taharuddin, S. (2018). Current Trends, Issues and Challenges Of Education And Language Studies. (E. A. Erda Wati Bakar, Ed.) Kuala Lumpur: Universiti Pertahanan Nasional Malaysia. 